\title{
Molecular characterization, overexpression and comparison of esterases-encoding LipRT, Lip4 and Lip20 from moderately thermophilic and mesophilic bacteria
}

\author{
Yu-Pei Chen ${ }^{1}$, Shu-Shan Liang ${ }^{2}$, Ing-Er Hwang ${ }^{2}$, Mei-Chih Chien ${ }^{2}$, Guey-Horng Wang ${ }^{1}$ and \\ Li-Ling Liaw ${ }^{2, a}$ \\ ${ }^{1}$ Application Technique Engineering Center of Natural Cosmeceuticals, College of Fuijan Province, Xiamen Medical \\ College, China \\ ${ }^{2}$ Bioresource Collection and Research Center, Food Industry Research and Development Institute, Taiwan
}

\begin{abstract}
Thermostable enzymes have the potential as the biocatalyst for industrial applications. To compare the relationship of enzymatic thermostability, the moderately thermophilic and mesophilic bacteria were utilized to explore the properties of esterases. By using the shotgun libraries of mesophilic Thalassomonas agarivorans, and Aeromonas sp., and moderately thermophilic Ralstonia sp., esterases-encoding Lip20, Lip4 and LipRT for $\alpha / \beta$ hydrolase fold were cloned, sequenced, and characterized. According to the recombinant proteins overexpressed by Escherichia coli, these results indicated that Lip20, Lip4 and LipRT preferred to hydrolyze short-length p-nitrophenyl ( $p$-NP) esters. The optimal temperature required for the activity of Lip20, Lip4 and LipRT was 30,40 and $60^{\circ} \mathrm{C}$, respectively, corresponding to the trend of bacterial growth temperature. Even at low temperature, coldadapted Lip4 from Aeromonas sp. revealed well enzymatic activity. In addition, after $60 \mathrm{~min}$ incubation between $40-60^{\circ} \mathrm{C}$, over $92 \%$ residual activity can be retained by the thermostable analysis of LipRT from Ralstonia sp.. Inspecting the predicted structures and amino acid composition, we found that the high helix content was exhibited in LipRT. Also, high frequency residues of Val, Phe and Arg for increasing hydrophobic and salt-bridge interactions were observed. These factors could improve LipRT thermal stabilization and lead to become more rigid.
\end{abstract}

\section{Introduction}

The worldwide demand for enzymes is increasing, and expenditure on enzymes is expected to reach $\$ 6.9$ billion by 2017 . Lipolytic enzymes account for $21 \%$ of the worldwide industrial enzyme market and are the third largest commercialized enzymes after proteases and carbohydrases [1]. They are widely present in animals, plants, and microorganisms. According to the capacity for hydrolyzing carboxyl esters of different acylglycerol lengths, lipolytic enzymes can be divided into two major groups: triacylglycerol acylhydrolases (lipases) (EC 3.1.1.3) and carboxylic-ester hydrolases (esterases) (EC 3.1.1.1).

\footnotetext{
${ }^{a}$ Corresponding author : 111@firdi.org.tw

(C) The Authors, published by EDP Sciences. This is an open access article distributed under the terms of the Creative Commons Attribution License 4.0 (http://creativecommons.org/licenses/by/4.0/).
} 
Lipolytic enzymes are used in various industrial areas, such as food, bioremediation, pharmaceuticals, detergents, biodiesel production, and waste treatment [2]. Therefore, the development of high-yield production and thermostable lipolytic has attracted considerable attention. Over the past years, a considerable number of studies have been made on the thermostability by structural comparison of enzymes between the different optimal temperatures [3]. In addition, according to the different amino acid composition between thermophilic and mesophilic proteins, thermostable features can provide guidelines for the design of thermo-tolerance proteins [4].

The hot-adapted esterases can be explored from thermophilic bacteria which represent a valuable source towards numerous applications. In this study, the esterases were carried out to explore the thermostable relationship between moderately thermophilic and mesophilic bacteria. Hence, the novel esterases, Lip20, Lip4 and LipRT from mesophilic T. agarivorans and Aeromonas sp., and moderately thermophilic Ralstonia sp., were successfully cloned and overexpressed in E. coli for characterization and comparison.

\section{Materials and methods}

\subsection{Shotgun library construction, sequencing and phylogenetic analysis}

The three bacterial strains isolated and purified from Hsinchu, Taiwan were capable of hydrolyzing tributyrin by agar plate determination. They were identified as Aeromonas sp., Ralstonia sp. and T. agarivorans. T. agarivorans was incubated in Polypepton-Yeast (PY) medium at $25^{\circ} \mathrm{C}$ for $3 \mathrm{~d}$. The Aeromonas sp. and Ralstonia sp. were incubated in Tryptic Soy Broth (TSB) medium at $30^{\circ} \mathrm{C}$ and $40^{\circ} \mathrm{C}$ for $3 \mathrm{~d}$, respectively. The bacterial pellet was harvested for genomic extraction. The shotgun library and DNA sequencing were performed as described in Liang et al. [5]. Putative open reading frames were further searched and examined using the protein BLAST program available on the NCBI website (https://blast.ncbi.nlm.nih.gov/Blast.cgi). The phylogenetic tree of the esterase gene was constructed using the neighbor-joining method by using MEGA 6.0 software with 1000 bootstrap replicates. Protein structure prediction was carried out using SWISS-MODEL [6] and the results were implemented in PyMol (www.pymol.org).

\subsection{Esterase expression plasmid construction and overexpression in E. coli}

To amplify the esterase genes from T. agarivorans, Aeromonas sp. and Ralstonia sp., the forward primers 5'-CACCATGCGAGGTATAGCGAGC-3'，5'-CACCATGAGCATATCGGTAGAG-3' and 5'-CACCATGGACAGGCAAGCCA CG-3' (underlined sequence was designed for ligation with the pET151/D-TOPO plasmid) and the reverse primers 5'-TTATTTGTTTACGAATCTGGC-3', 5'TTAGCCAACAAAATCTCGA-3' and 5'-TCAACGCCCGCCCGCACC-3' were used for polymerase chain reaction (PCR). A Champion pET151 Directional TOPO Expression Kit (Invitrogen, Carlsbad, CA, USA) was used to obtain the esterase overexpression plasmids. Three esterase overexpression plasmids were transformed into competent cells of E. coli C41(DE3), E. coli C43(DE3), and E. coli BL21(DE3). For purifying the esterase protein, a Ni-NTA purification system (Invitrogen) was used. Protein content was determined using a Bradford protein assay kit (Bio-Rad, Hercules, CA) and monitored using SDS-PAGE and colloidal Coomassie blue staining.

\subsection{Enzymatic activity assay of the esterase protein}

Enzyme activity was determined using a spectrophotometric assay with $p$-nitrophenyl ( $p$-NP) esters as substrates. Various $p$-NP esters were estimated, including $p$-NP butyrate (C4), $p$-NP valerate (C5), $p$ NP octanoate (C8), $p$-NP decanoate $(\mathrm{C} 10), p$-NP dodecanoate $(\mathrm{C} 12), p$-NP myristate $(\mathrm{C} 14)$, and $p$-NP 
palmitate (C16). The mixture used in the enzyme activity assay contained $0.25 \mathrm{mM} p$-NP esters (C4$\mathrm{C} 10), 2.5 \%$ ethanol, $50 \mathrm{mM}$ Tris- $\mathrm{HCl}(\mathrm{pH} \mathrm{7.4)}$, and a final volume of $800 \mu \mathrm{L}$ of esterase. For determining long-chain $p$-NP esters $(\mathrm{C} 12-\mathrm{C} 16), 0.2 \mathrm{mM} p$-NP esters, $2.5 \%$ ethanol, $0.1 \%$ gum arabic, $0.1 \%$ deoxycholate, $50 \mathrm{mM}$ Tris- $\mathrm{HCl}(\mathrm{pH} 7.4)$, and esterase were added. The reaction mixtures were incubated at different temperatures or $\mathrm{pH}$ for $10 \mathrm{~min}$ and interrupted by incubation at $100^{\circ} \mathrm{C}$. The mixture was then measured at OD405 by using a spectrophotometer.

\section{Results and discussion}

\subsection{Genomic library of Lip20, Lip4 and LipRT, and identification of the esterase genes}

Three genomic libraries of T. agarivorans, Aeromonas sp. and Ralstonia sp. containing over 15,000 clones with 2-4-kb DNA inserts was constructed. Three clones from T. agarivorans, Aeromonas sp. and Ralstonia sp. libraries produced significantly clear zones, indicating that they were capable of producing esterases, and were selected for shotgun sequencing. The sequencing reads were assembled and insertions showed the full open reading frames for BLAST analysis. The results revealed three genes with 927-bp, 765-bp and 1263-bp esterases which were named as lip20, lip4 and lipRT (GenBank accession nos. KR401219, KX756573 and KX756574). The deduced sequences of Lip20, Lip4 and LipRT had 308, 254 and 420 amino acids, suggesting the calculated molecular weights of $34.1,28.2$ and $45.5 \mathrm{kDa}$. They respectively shared 53\%, 97\% and 99\% identities with the sequences of Shewanella frigidimarina lipase, Aeromonas veronii pimeloyl-[acyl-carrier protein] methyl ester esterase and Ralstonia mannitolilytica serine hydrolase (GenBank accession no. WP_011638606, WP_005340633.1 and WP_045218811.1), which remain uncharacterized and unpublished.

(a)

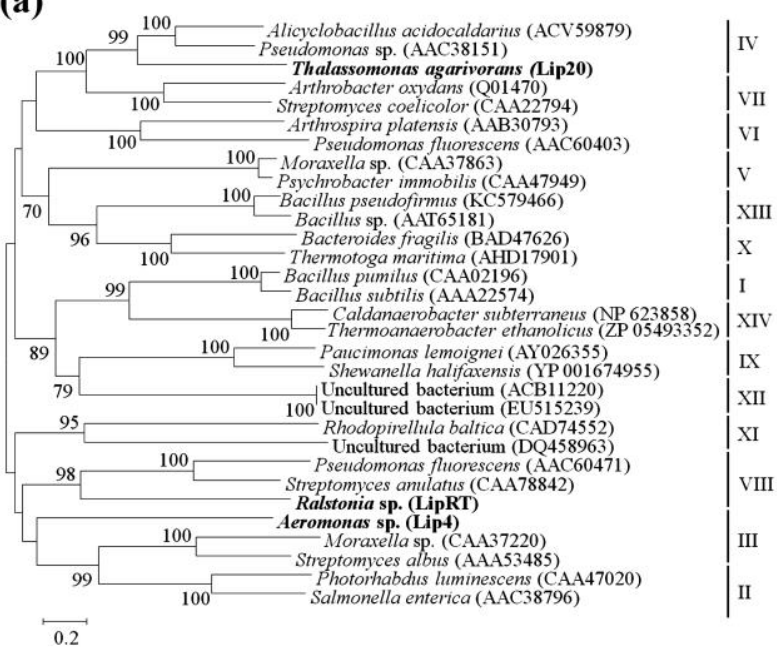

(b)
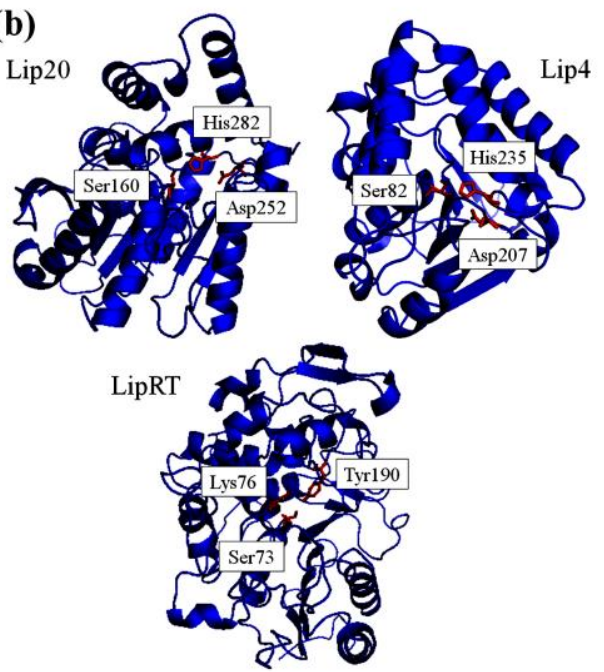

Figure 1. Phylogenetic tree and structure prediction of the Lip20, Lip4 and LipRT. (a) Phylogeny based on the complete open reading frame of esterase sequences of 14 families from T. agarivorans, Aeromonas sp., Ralstonia sp. and various bacteria. (b) The protein structures were predicted by SWISS-MODEL and implemented in PyMol.

The 14 families of lipolytic enzymes identified by Rao et al. [7] were used for constructing a phylogenetic tree. Figure 1a shows that Lip20, Lip4 and LipRT were classified into the Family IV, III and VIII clades. Moreover, considerable research has been conducted on the three-dimensional structures of esterases, which show the conserved $\alpha / \beta$-hydrolase fold [2]. The protein structures of Lip20, Lip4 and LipRT were predicted by using SWISS-MODEL [6] and the results are shown in Figure 1b. The predicted catalytic triads were observed at Ser160, Asp252, and His282 for Lip20 and 
Ser82, Asp207, and His235 for Lip4. Moreover, Lip20 and Lip4 shared the consensus sequences of glycine-Xaa-serine-Xaa-glycine at residues 158 to 162 and 80 to 84, respectively [2]. The Family VIII is different from Family III and IV without G-X-S-X-G motif [8]. The predicted catalytic triad of LipRT was observed at Ser73, Lys76 and Tyr190. Furthermore, LipRT shared the consensus sequences of serine-Xaa-Xaa-lysine between 73 and 76 residual, like the class $\mathrm{C} \beta$-lactamase.

\subsection{Construction and characterization of recombinant esterase}

The expression plasmids harboring lip20, lip4 and lipRT were transferred into E. coli BL21(DE3), E. coli $\mathrm{C} 41(\mathrm{DE} 3)$, and $E$. coli $\mathrm{C} 43(\mathrm{DE} 3)$. The results indicated that the clones with $E$. coli $\mathrm{C} 41(\mathrm{DE} 3)$ and E. coli $\mathrm{C} 43(\mathrm{DE} 3)$ formed a more marked clear zone than did those with E. coli BL21(DE3)(Fig. 2). Low esterase activity in E. coli BL21(DE3) may be due to hydrophobicity, resulting in protein aggregation [9]. Our result can provide the advice to the recombinant proteins leading to the production of insoluble inclusion bodies in E. coli. The selection of appropriate host can reduce the complex refolding process of recombinant proteins and has the potential to apply in industry. Therefore, E. coli C43(DE3) was used for protein overexpression and esterase activity analysis. After protein purification was performed using a nickel column and the three proteins were analyzed using SDS-PAGE, the three major bands were observed (Fig. 2). The expected molecular weights of the Lip20, Lip4 and LipRT-fused polyhistidine-tag were 37.9, 32 and 49.3 kDa.

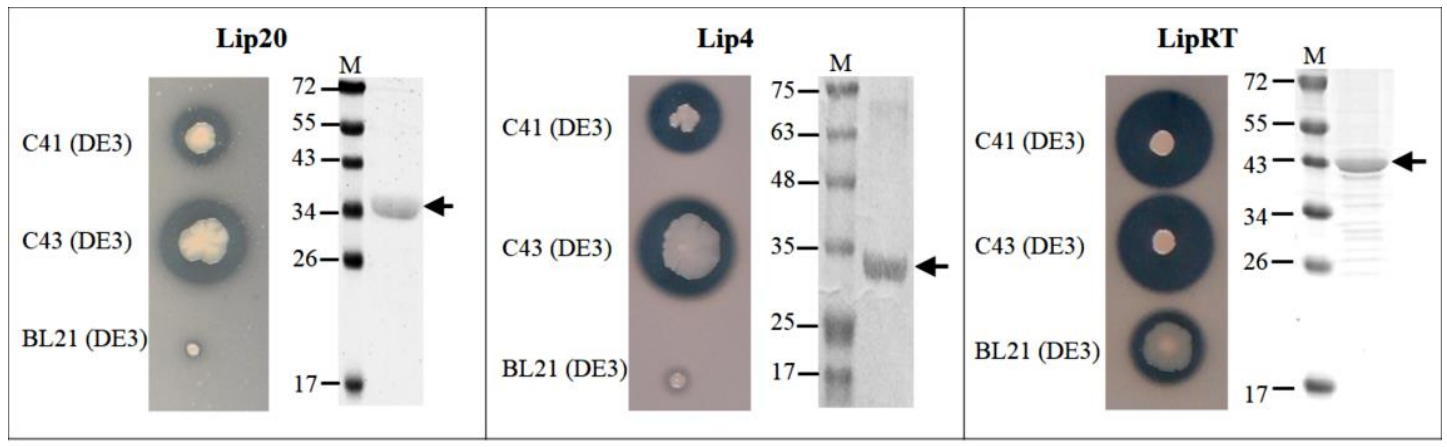

Figure 2. Overexpression of lip20, lip4 and lipRT in E. coli. For observing esterase activities, transformants with E. coli C41(DE3), E. coli C43(DE3), and E. coli BL21(DE3) harboring Lip20, Lip4 and LipRT were spread on an LB agar plate with $0.01 \%$ arabinose, $0.4 \mathrm{mM}$ IPTG, $1 \%$ tributyrin, and $12.5 \mu \mathrm{g} / \mathrm{mL}$ chloramphenicol. Recombinant Lip20, Lip4 and LipRT proteins in E. coli C43(DE3) were purified and performed by SDS-PAGE analysis.

\subsection{Esterase activity assay}

For demonstrating the esterase activity of recombinant Lip20, Lip4 and LipRT, various $p$-NP esters were used as substrates. The results showed the hydrolytic activities of recombinant Lip20, Lip4 and LipRT toward p-NP butyrate (C4) and $p$-NP valerate (C5) of short-length $p$-NP esters (Fig. 3). When the $p$-NP ester chain was over $p$-NP octanoate (C8), the activity of Lip4 was lower than $7.9 \%$ and no activity was detected with Lip20. However, the activity of LipRT was still maintained with 53.2\% using $p$-NP octanoate (C8). Little activity of LipRT was determined as over $p$-NP dodecanoate (C12). The temperature and $\mathrm{pH}$ profiles of the recombinant Lip20, Lip4 and LipRT were further analyzed. The optimal temperatures of Lip20, Lip4 and LipRT were 30, 40 and $60^{\circ} \mathrm{C}$, respectively. Nevertheless, the residual activity of Lip 20 remained $39 \%$ at $40^{\circ} \mathrm{C}$ and was completely lost at $60^{\circ} \mathrm{C}$. The Lip4 activity still had $32.2 \%$ at $60^{\circ} \mathrm{C}$. Even at low temperature of 10 and $20^{\circ} \mathrm{C}, 58.7 \%$ and $77.1 \%$ of relative activity can be achieved. This implied that the Lip4 was regarded to be the cold-adapted enzyme. It can offer the novel opportunities as the biocatalyst exploitation in food industry, medical, domestic and environmental application [10]. Interestingly, the LipRT possessed the tolerance of high 
temperature and its activity maintained $82 \%$ at $65^{\circ} \mathrm{C}$. Accordingly, a correlation existed between bacterial growth temperature and optimal temperature of enzymatic activity [11]. The $\mathrm{pH}$ profiles of Lip20, Lip4 and LipRT activity indicated that residual activities were $56.3 \%-100 \%, 39.4 \%-93.1 \%$ and $70.9 \%-100 \%$ at $\mathrm{pH} 7-8.6$ with Tris- $\mathrm{HCl}$ buffer. With phosphate buffer, esterase activities of Lip20, Lip4 and LipRT were $8.5 \%-83 \%, 7.3 \%-100 \%$ and $18.7 \%-83.9 \%$ at $\mathrm{pH} 7-6$. Furthermore, the relative activities of Lip20 and Lip4 were $33.5 \%-33 \%$ and $71.6 \%-40.9 \%$ at $\mathrm{pH} 8.6$ and $\mathrm{pH} 9.0$, respectively, with boric acid/ $\mathrm{NaOH}$ buffer. However, no activity was detected with LipRT at $\mathrm{pH} 8.6$ and 9.0. This revealed that the three enzymes preferred to potassium phosphate rather than $\mathrm{Tris}-\mathrm{HCl}$ at $\mathrm{pH}$ 7. On the contrary, they were suitable for Tris- $\mathrm{HCl}$ instead of boric acid/ $\mathrm{NaOH}$ at $\mathrm{pH} 8.6$. The different buffer system acquires the different activities of esterases. Consequently, the specific activity of esterase was detected using the preferred substrate, optimal temperature and $\mathrm{pH}$. The results of Lip20, Lip4 and LipRT specific activities were 42.4, 11.7 and $15.2 \mathrm{U} / \mathrm{mg}$, respectively.

(a)

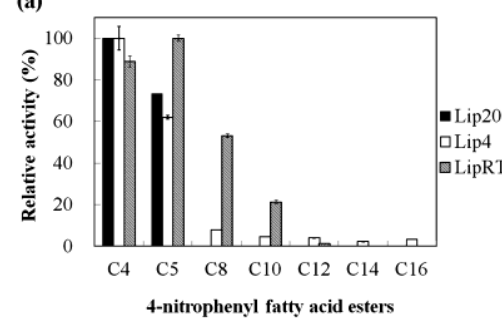

(c)

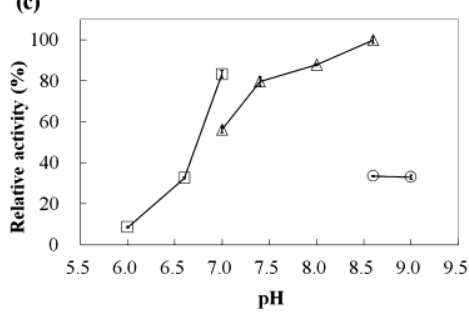

(d)

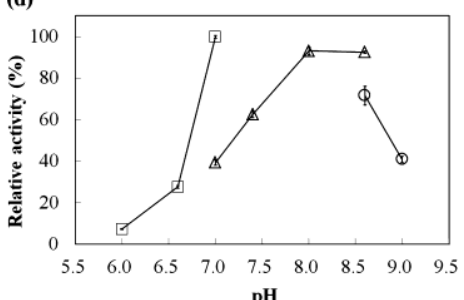

pH

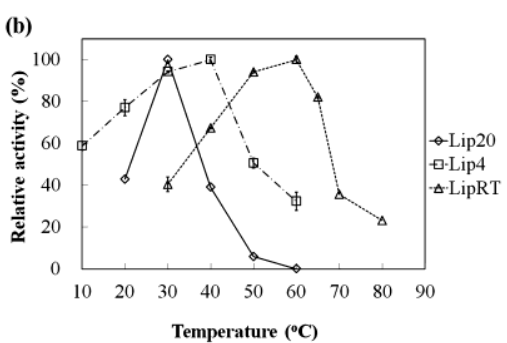

(e)

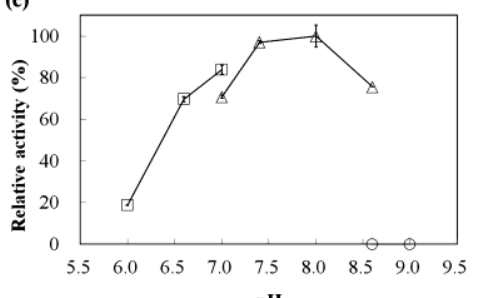

Figure 3. The optimal substrate, temperature and $\mathrm{pH}$ analyses of recombinant Lip20, Lip4 and LipRT activities. (a) Lip20, Lip4 and LipRT activities toward various p-nitrophenyl esters were assessed. Reaction mixtures were incubated at $30^{\circ} \mathrm{C}$ and $\mathrm{pH} 7.4$ with Tris $-\mathrm{HCl}$ buffer for $10 \mathrm{~min}$ and interrupted by incubation at $100^{\circ} \mathrm{C}$. (b) The temperature profiles of Lip20, Lip4 and LipRT were measured at $10^{\circ} \mathrm{C}-80^{\circ} \mathrm{C}$ and $\mathrm{pH} 7.4$ with Tris- $\mathrm{HCl}$ buffer for 10 min using $p$-NP butyrate (C4). The $\mathrm{pH}$ profiles of (c) Lip20, (d) Lip4 and (e) LipRT were determined at 30, 40 and $60^{\circ} \mathrm{C}$ with potassium phosphate buffer ( $\mathrm{pH}$ 6-7), Tris- $\mathrm{HCl}$ buffer ( $\left.\mathrm{pH} 7-8.6\right)$, and boric acid/NaOH buffer (pH 8.6-9) for 10 min using $p$-NP butyrate (C4).

\subsection{Effect of thermostability on Lip20, Lip4 and LipRT}

The various temperatures were conducted for thermostable analysis of Lip20, Lip4 and LipRT from 0 to 60 min (Fig. 4). The result revealed that the LipRT was more thermostable than Lip20 and Lip4 in correspondence with the optimal temperature of enzymatic activities. The Lip20 and Lip4 activities were dramatically drop to $45 \%$ and $1.6 \%$ after $15 \mathrm{~min}$ incubation at $50^{\circ} \mathrm{C}$. The cold-adapted enzymes generally have a low thermal stability [10]. The result of Lip4 was corresponding to this finding. Additionally, over $92 \%$ relative activities of LipRT were retained for $60 \mathrm{~min}$ between $40^{\circ} \mathrm{C}$ and $60^{\circ} \mathrm{C}$. The half-life, the time over which the $50 \%$ activity is lost, of LipRT was approximately maintained for $26 \mathrm{~min}$ at $70^{\circ} \mathrm{C}$. This result suggested that the LipRT was a thermostable protein and superior to previous study, an alkaline lipase from Ralstonia [12].

Several structural features have been explained that could contribute to thermostability, including an increased protein hydrophobicity, additional salt bridges, a decreased number of cavities, an increased helix stability, a decreased chain flexibility and so forth [3]. In this study, the helix content 
of thermostable LipRT was higher than those of Lip20 and Lip4, and was an important role for thermal resistance (Table 1) [3]. Even if the helix content of MtEst45 from Microbulbifer thermotolerans was not as high as other thermally tolerant esterases, increasing $\beta$-sheet contents may contribute to the enzymatic stabilization [13]. In addition, some high frequency residues for facilitating thermostability, such as Val, Phe and Arg, were recognized in LipRT. These residues may lead to reinforce the hydrophobic and salt-bridge interactions.
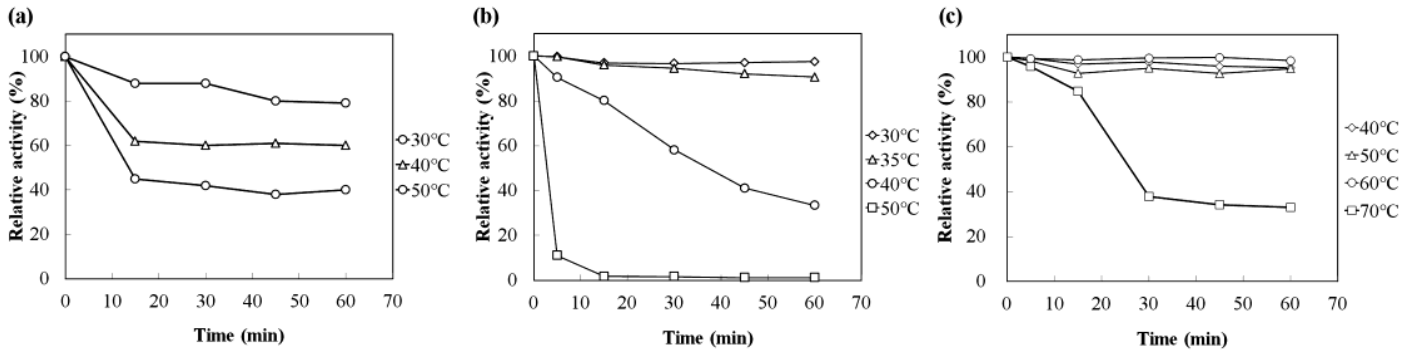

Figure 4. The thermostable analyses of Lip20, Lip4 and LipRT relative activities. The (a) Lip20 and (b) Lip4 were pre-incubated from $30-50^{\circ} \mathrm{C}$ by the time course from 0 to $60 \mathrm{~min}$. The (c) LipRT was pre-incubated from $40-70^{\circ} \mathrm{C}$ by the time course from 0 to $60 \mathrm{~min}$. Then, the remaining Lip20, Lip4 and LipRT enzymatic activities were measured at 30,40 and $60^{\circ} \mathrm{C}$ and $\mathrm{pH} 8.6,7$ and 8 for $10 \mathrm{~min}$, respectively.

Table 1. Properties of the esterases from Lip20, Lip4, LipRT, various bacteria and metagenome.

\begin{tabular}{|c|c|c|c|c|c|c|c|}
\hline \multirow[b]{2}{*}{$\begin{array}{l}\text { Esterase } \\
\text { family }\end{array}$} & \multirow[b]{2}{*}{ Esterase } & \multirow[b]{2}{*}{$\begin{array}{l}\text { Bacterial } \\
\text { growth } \\
\text { temperature }\end{array}$} & \multicolumn{4}{|c|}{ Esterases properties } & \multirow[b]{2}{*}{ Reference } \\
\hline & & & $\begin{array}{c}\text { Optimal } \\
\text { temperature } \\
\text { activity }\end{array}$ & $\begin{array}{c}\text { Residual } \\
\text { activity of } \\
\text { thermostability }^{\mathrm{a}}\end{array}$ & $\begin{array}{c}\alpha- \\
\text { helix }\end{array}$ & $\begin{array}{c}\beta- \\
\text { sheet }\end{array}$ & \\
\hline \multirow{3}{*}{ III } & Lip4 & $30^{\circ} \mathrm{C}$ & $40^{\circ} \mathrm{C}$ & $1 \%$ & 11 & 8 & This study \\
\hline & EstA & - & $45^{\circ} \mathrm{C}$ & $0 \%$ & 11 & 10 & [14] \\
\hline & MtEst45 & $37^{\circ} \mathrm{C}$ & $46^{\circ} \mathrm{C}$ & $30 \%$ & 10 & 20 & {$[15]$} \\
\hline \multirow{3}{*}{ IV } & Lip20 & $25^{\circ} \mathrm{C}$ & $30^{\circ} \mathrm{C}$ & $40 \%$ & 9 & 10 & This study \\
\hline & LipP & $28^{\circ} \mathrm{C}$ & $45^{\circ} \mathrm{C}$ & $47 \%$ & 9 & 10 & [16] \\
\hline & REst1 & $37^{\circ} \mathrm{C}$ & $50^{\circ} \mathrm{C}$ & $\sim 75 \%$ & 12 & 9 & [17] \\
\hline \multirow{3}{*}{ VIII } & LipRT & $40^{\circ} \mathrm{C}$ & $60^{\circ} \mathrm{C}$ & $95 \%$ & 13 & 9 & This study \\
\hline & PBS-2 & $25^{\circ} \mathrm{C}$ & $50^{\circ} \mathrm{C}$ & $80 \%^{\mathrm{c}}$ & 11 & 10 & {$[18]$} \\
\hline & EstC & $25^{\circ} \mathrm{C}$ & $30^{\circ} \mathrm{C}$ & - & 12 & 9 & [19] \\
\hline
\end{tabular}

${ }^{a}$ The residual activities of esterases were detected after $50^{\circ} \mathrm{C}$ incubation for $1 \mathrm{~h}$.

${ }^{\mathrm{b}}$ The secondary structures of $\alpha$-helix and $\beta$-sheet was predicted and referenced by YASPIN and SWISS-MODEL $[6,20]$.

${ }^{c}$ The PBS-2 residual activity was determined after $50^{\circ} \mathrm{C}$ incubation for $0.5 \mathrm{~h} \mathrm{[18].}$

\section{Conclusions}

Lip20, Lip4 and LipRT encoding esterases were cloned from mesophilic T. agarivorans and Aeromonas sp., and moderately thermophilic Ralstonia sp., and successfully overexpressed in E. coli. These enzymes were $\alpha / \beta$-hydrolase structures and were capable of hydrolyzing short-length $p$ nitrophenyl esters. Moreover, the optimal temperature of esterase activities was in agreement with the bacterial growth temperature. Better thermostability of enzymatic activity was observed by LipRT from Ralstonia sp.. According to the comparison of predicted structures, the helix contents may play a critical factor to enhance the enzymatic thermostability. On the other hand, the cold-adapted Lip4 from Aeromonas sp. also revealed well enzymatic activity at low temperature, whereas the weak thermostable ability was perceived. Further study of these esterases, including the X-ray structure and 
site-directed mutagenesis analysis, will clarify the conformational difference and ion interactions for thermostability.

\section{Acknowledgments}

This work was supported by the Bureau of Energy, Ministry of Economic Affairs, Taiwan under Grant No. 106-D0111.

\section{References}

1. F. Hasan, A.A. Shah and A. Hameed, Enzyme. Microb. Tech., 39, 235-251 (2006)

2. L. Casas-Godoy, S. Duquesne, F. Bordes, G. Sandoval and A. Marty, Methods Mol. Biol., 861, 3$30(2012)$

3. X.X. Zhou, Y.B. Wang, Y.J. Pan and W.F. Li, Amino Acids, 34, 25-33 (2008)

4. H. Yu and H. Huang, Biotechnol. Adv., 32, 308-315 (2014)

5. S.S. Liang, Y.P. Chen, Y.H. Chen, S.H. Chiu and L.L. Liaw, J. Appl. Microbiol., 116, 563-572 (2014)

6. M. Biasini, S. Bienert, A. Waterhouse, K. Arnold, G. Studer, T. Schmidt, F. Kiefer, T.G. Cassarino, M. Bertoni, L. Bordoli and T. Schwede, Nucleic Acids Res., 42, W252-258 (2014)

7. L. Rao, Y. Xue, Y. Zheng, J.R. Lu and Y. Ma, PLoS One, 8, e60645 (2013)

8. J.L. Arpigny and K.E. Jaeger, Biochem. J., 343, 177-183 (1999)

9. X.Z. Lin, S.S. Cui, G.Y. Xu, S.A. Wang, N. Du and J.H. Shen, Polar Res., 29, 421-429 (2010)

10. B. Joseph, P.W. Ramteke and G. Thomas, Biotechnol. Adv., 26, 457-470 (2008)

11. P.J. Haney, M. Stees and J. Konisky, J. Biol. Chem., 274, 28453-28458 (1999)

12. H.Y. Yoo, J.R. Simkhada, S.S. Cho, D.H. Park, S.W. Kim, C.N. Seong and J.C. Yoo, Bioresour. Technol., 102, 6104-6111 (2011)

13. C. Niu, L. Zhu, P. Zhu and Q. Li, J. Agric. Food Chem., 63, 5249-5256 (2015)

14. X. Chu, H. He, C. Guo and B. Sun, Appl. Microbiol. Biotechnol., 80, 615-625 (2008)

15. Y.S. Lee, Front. Microbiol., 7, 218 (2016)

16. D.W. Choo, T. Kurihara, T. Suzuki, K. Soda and N. Esaki, Appl. Environ. Microbiol., 64, 486491 (1998)

17. A.P. Virk, P. Sharma and N. Capalash, J. Microbiol. Biotechnol., 21, 667-674 (2011)

18. Y.O. Kim, I.S. Park, B.H. Nam, D.G. Kim, Y.J. Jee, S.J. Lee and C.M. An, J. Microbiol. Biotechnol., 24, 1260-1268 (2014)

19. Y.S. Kim, H.B. Lee, K.D. Choi, S. Park and O.J. Yoo, Biosci. Biotechnol. Biochem., 58, 111-116 (1994)

20. K. Lin, V.A. Simossis, W.R. Taylor and J. Heringa, Bioinformatics, 21, 152-159 (2005) 